\title{
Microbiology Susceptibility Supplemental Qualifiers Dataset
}

National Cancer Institute

\section{Source}

National Cancer Institute. Microbiology Susceptibility Supplemental Qualifiers Dataset. NCI Thesaurus. Code C147227.

A dataset containing supplemental information, specifically non-standard variables, to parent records in the microbiology susceptibility domain. 